\title{
CORRECTIONS
}

\section{Neuropathic pain: mechanisms and their clinical implications}

The definition of neuropathic pain was inconsistently described in this State of the Art article (BMJ 2014;348:f7656, doi:10.

$1136 / \mathrm{bmj} . \mathrm{f} 7656)$. The newer definition of neuropathic pain as "pain caused by a lesion or disease of the somatosensory nervous system" was used by the authors in the box labelled

"Definitions." However, in the main text of the article and the

"Summary points" box, neuropathic pain was described using an older definition: "pain resulting from injury to, or dysfunction of, the somatosensory system." For more of the authors' discussion of this point, please see their rapid response at http: //www.bmj.com/content/348/bmj.f7656/rr/690558

Cite this as: BMJ 2014;348:g2323

๑ BMJ Publishing Group Ltd 2014 